\title{
The development of protocols and norms for sports vision evaluations
}

\author{
JHC Buys and JT Ferreira
}

Academy of Sports Vision, Department of Optometry, University of Johannesburg, PO Box 524, Auckland Park, 2006 Republic of South Africa

<jferreira@uj.ac.za>

Received 5 June 2008; revised version accepted 28 September 2008

\begin{abstract}
The purpose of this study was to find the most appropriate protocol to establish norms for the most important visual skills required by elite athletes in sports performance. One hundred and fifty eight elite athletes were tested and their visual skills categorized as being: superior, above average, average, ineffective or needs immediate atten-
\end{abstract}

tion. Two methods namely, the percentage method and the mean and standard deviation method were employed to find the most applicable way to establish these categories. The results indicate that elite athletes perform very well for all the visual skills tested and that the norms thus established suggest the importance of these visual skills in sports performance.

\section{Introduction}

Reichow and Stern ${ }^{1}$ formulated the following definition. Sports Vision encompasses performance oriented comprehensive vision care programmes involving the education, evaluation, correction, protecting, and enhancement of the athlete. Each of the above areas should be addressed in a performance-orientated manner. Improved visual performance resulting in enhanced athletic performance must be the ultimate goal of sports vision regimens ${ }^{1}$. To be able to reach this goal, various aspects regarding sports vision should be further researched. One such aspect is the development of norms and protocols in the testing and the evaluation of the elite athlete. If these can be established, athlete's results can be categorized and compared. Using standardized procedures would then allow researchers to move to the next level and that is to determine sport specific visual skills.

Vision is our dominant sense: Approximately 70\% of all sensory receptors in the body are in the eyes and according to Marieb and Mallat ${ }^{2}$ visual skills and their components comprise around $80 \%$ of the manner in which athlete's obtain information about the sportive environment. Although there is still a search for the factors underlying successful performance of sport skills, the latest evidence by Abernethy ${ }^{3}$ suggest that the role of visual skill enhancement for sports vision is of critical importance to sport success.

Modern professional sport is big business. In 1998 the world sponsorship market was estimated at over US \$20 billion, with sport sponsorships accounting for US $\$ 14$ billion of that amount ${ }^{4}$. Winning is the name of the game and athletes are trying almost anything to get an edge on their opponents. Athletes are beginning to realize, that the demands on the visual system during athletic performance, are among the most rigorous of any activity, and that visual skills needs as much of their training time as does other key performance indicators.

Planer $^{5}$ and Coffey and Reichow ${ }^{6}$ attempted to establish norms for the evaluation of athletes. Planer ${ }^{5}$ categorized the visual skills into five categories of competence on a very arbitrary basis, whereas Coffey and Reichow ${ }^{6}$ only established mean and standard deviation values for selected visual skills. The problem with the above studies was that almost none 
of the instruments they used to test visual skills are still in use today. There is thus a need for a sports vision protocol based on a scientific system whereby all athletes' visual skills can be evaluated. Only once this system is in place, can attention be given to the development of meaningful vision performance enhancement programmes.

\section{Methods}

The primary aim of this study was to establish norms for the visual skills (including visual-perceptual and visual-motor skills) that would form part of a general sports vision testing battery, and then divides every skill into five different categories of competency namely: Superior, Above Average, Average, Ineffective, and Needs Immediate Attention.

All of the athletes tested were identified by SISA South Africa (Sports Information and Science Agency) as extremely talented, being either athletes that had previously competed at international level or athletes that are up and coming stars of the future. Athletes were tested at the University of Johannesburg's Academy of Sports Vision. One hundred and fifty eight athletes were included in the study. Their ages ranged from 16 to 28 years and 64 of them being female and 94 males. It was specifically decided not to separate the group into age, gender and sport but to establish an overall picture. Future studies can then investigate the impact of different variables on these results.

Since there are no standardized methods in use, two new methods were developed to define the norms for the different categories:

\section{Percentage Method}

Every visual skill was divided into a superior, above average, average, ineffective and needs immediate attention category. The top 10 percent of the results of the athletes tested were categorized as Superior. From 90 to 70 percent were categorized as Above Average and 70 to 50 percent as Average. The remaining 50 percent of the athletes were categorized in only two groups that were divided equally. From 50 to 25 percent were categorized as Ineffective and from 25 to 0 percent (which is the lowest 25 percent scores, scored in a test) as Needs Immediate Attention.

Mean and standard deviation method

Secondly for the mean and standard deviation method, the same categories were used for the different visual skills, (namely superior, above average, average, ineffective and needs immediate attention) but their values were calculated differently. The mean and standard deviation values were calculated for all the different visual skills. Average categories were calculated by adding the standard deviation value to the mean value. For instance if the mean value of a visual skill test done was calculated to be 36 and the standard deviation 8, the values for the Average category would be between 44 and 36. The Above Average categories would then be calculated by adding another standard deviation value to the maximum $A v$ erage category value (which would in this case be 44) and the Above Average category would be between 44 and 52. The Superior category value would then be any value higher or better than the above average category value, which in this example would be any value higher than 52, that is, values larger than the mean plus three standard deviations.

The Ineffective category would be calculated the same as the above, with the exception that the standard deviation value would be subtracted from the minimum value of the Average category (which in our example was 36 and was also the mean value). So the Ineffective category would be between 28 and 36. The Needs Immediate Attention category would then be any value lower or worst than the ineffective category value, which would be any value lower than 28 . The values generated using the methods described above were rounded off to the nearest integer, as these integer values facilitate ease of clinical comparison of the data.

The statistical analysis was conducted by STATCON, the statistical consultation service of the University of Johannesburg. Athletes were allowed to use a refractive compensation only if they were using it when participating in their sport. For a full explanation of all the methods used for testing these skills Buys ${ }^{7}$ can be consulted.

\section{Results}

The results present the most appropriate method of the two methods employed to determine the different categories of competence. Visual skills, in which a minimum and or maximum score could be obtained, the mean and standard deviation method generated results that did not make sense. The values obtained 
for the superior group either exceeded the maximum score (contrast sensitivity, reaction eye-hand coordination and visualization), or resulted in values $<0.00$ (colour vision, stereopsis and visual adjustability). Thus the norms for these skills were all calculated by using the percentage method, while the norms for all the other skills were determined by using the mean and standard deviation method. The results that follow also indicate the specific protocol used to obtain the various norms.

Table 1: The norms for Static Visual Acuity as obtained with the use of a Snellen VA chart and a testing distance of 6 metres.

\begin{tabular}{|l|c|c|c|}
\hline & Right eye & Left eye & Both eyes \\
\hline SUPERIOR: & $>6 / 3$ & $>6 / 3$ & $>6 / 3$ \\
\hline ABOVE AVERAGE: & $6 / 3-6 / 4.5$ & $6 / 3-6 / 4.5$ & $6 / 3-6 / 4.5$ \\
\hline AVERAGE: & $6 / 5-6 / 6$ & $6 / 5-6 / 6$ & $6 / 5-6 / 6$ \\
\hline INEFFECTIVE: & $6 / 6-6 / 7.5$ & $6 / 6-6 / 7.5$ & $6 / 6-6 / 7.5$ \\
\hline NEEDS IMMEDIATE ATTENTION & $<6 / 7.5$ & $<6 / 7.5$ & $<6 / 7.5$ \\
\hline
\end{tabular}

It is clear from Table 1 that the norms are the same for each eye and also when both eyes are used.

Table 2: The norms for Dynamic (kinetic) Visual Acuity as obtained with a Wayne Tachistoscope rotator

\begin{tabular}{|l|c|c|c|}
\hline & Right eye & Left eye & Both eyes \\
\hline SUPERIOR: & $>6 / 4$ & $>6 / 4$ & $>6 / 4$ \\
\hline ABOVE AVERAGE: & $6 / 4-6 / 5$ & $6 / 4-6 / 5$ & $6 / 4-6 / 5$ \\
\hline AVERAGE: & $6 / 5-6 / 7.5$ & $6 / 5-6 / 7.5$ & $6 / 5-6 / 6$ \\
\hline INEFFECTIVE: & $6 / 7.5-6 / 9$ & $6 / 7.5-6 / 9$ & $6 / 6-6 / 7.5$ \\
\hline NEEDS IMMEDIATE ATTENTION & $<6 / 9$ & $<6 / 9$ & $<6 / 7.5$ \\
\hline
\end{tabular}

Again the results are the same for right and left eye but with both eyes the norms are slightly higher. The norms are also lower than those obtained for static visual acuity.

Table 3: The norms obtained for Contrast Sensitivity by means of the Functional Acuity Contrast Test

\begin{tabular}{|l|l|}
\hline & Rows identified correctly \\
\hline SUPERIOR: & $\mathrm{A}, \mathrm{B}, \mathrm{C}, \mathrm{D}$ and $\mathrm{E}$ \\
\hline ABOVE AVERAGE: & $\mathrm{A}, \mathrm{C}, \mathrm{D}, \mathrm{E}$, and up to number 8 in row B \\
\hline AVERAGE: & $\mathrm{D}$ and up to number 8 in $\mathrm{A}, \mathrm{B}, \mathrm{C}$ and $\mathrm{E}$ \\
\hline INEFFECTIVE: & $\mathrm{B}, \mathrm{C}$, and D up to number 8 and A and E up to number 7 \\
\hline NEEDS IMMEDIATE ATTENTION & $\begin{array}{l}\mathrm{B}, \mathrm{C}, \text { and D any value below } 8 \text { and A and E any value } \\
\text { below 7. }\end{array}$ \\
\hline
\end{tabular}

These norms a quite high but in many sports environments good contrast sensitivity may be important. 
Table 4: The norms obtained for Colour Discrimination with the use of the Farnsworth D-15 colour vision test.

\begin{tabular}{|l|c|}
\hline & Number of errors \\
\hline SUPERIOR: & 0 \\
\hline ABOVE AVERAGE: & - \\
\hline AVERAGE: & - \\
\hline INEFFECTIVE: & 1 or 2 \\
\hline $\begin{array}{l}\text { NEEDS IMMEDIATE ATTEN- } \\
\text { TION }\end{array}$ & 3 Or more \\
\hline
\end{tabular}

Colour discrimination is typical example where even with the Percentage Method it was still not possible to do the ranking according to all five categories. Therefore it is suggested that Above average and Average be ignored.

Table 5: The norms obtained for Stereopsis with the use of a Randot Stereo test

\begin{tabular}{|l|c|}
\hline & Seconds of arc \\
\hline SUPERIOR: & 20 \\
\hline ABOVE AVERAGE: & 20 \\
\hline AVERAGE: & 20 \\
\hline INEFFECTIVE: & 25 to 30 \\
\hline $\begin{array}{l}\text { NEEDS IMMEDIATE ATTEN- } \\
\text { TION }\end{array}$ & $<30$ \\
\hline
\end{tabular}

All athletes must have binocular vision to be able to perform this test. It immediately implies that monocular athletes or athletes for whatever reason suppressing one eye will score very low.

Table 6: The norms obtained for Focus Flexibility (Accommodation) with the use of $+2.00 /-2.00$ dioptre at $40 \mathrm{~cm}$ and a pl/-2.00 dioptre flippers at 6 metres

\begin{tabular}{|l|c|c|}
\hline & $\begin{array}{c}\text { At } 40 \mathrm{~cm} \\
\text { number of cycles per } \\
\text { minute }\end{array}$ & $\begin{array}{c}\text { At } 6 \text { metres } \\
\text { number of cycles per } \\
\text { minute }\end{array}$ \\
\hline SUPERIOR: & 34 & 33 \\
\hline ABOVE AVERAGE: & 26 to 34 & 24 to 33 \\
\hline AVERAGE: & 17 to 25 & 15 to 23 \\
\hline INEFFECTIVE: & 8 to 16 & 6 to 14 \\
\hline $\begin{array}{l}\text { NEEDS IMMEDIATE ATTEN- } \\
\text { TION }\end{array}$ & $<8$ & $<6$ \\
\hline
\end{tabular}

There is very little difference in the norms determined for near $(40 \mathrm{~cm})$ and far $(6$ metres $)$, which is somewhat surprising. In most sports distance focus flexibility will be more important. 
Table 7: The norms obtained for Fusion Flexibility (Binocularity) with the use of 6 prism dioptres base in and 12 prism dioptres base out flippers at $40 \mathrm{~cm}$ and at 6 metres

\begin{tabular}{|l|c|c|}
\hline & $\begin{array}{c}\text { At } 40 \mathrm{~cm} \\
\text { number of cycles per } \\
\text { minute }\end{array}$ & $\begin{array}{l}\text { At } 6 \text { metres } \\
\text { number of cycles per } \\
\text { minute }\end{array}$ \\
\hline SUPERIOR: & 30 & 20 \\
\hline ABOVE AVERAGE: & 23 to 30 & 14 to 19 \\
\hline AVERAGE: & 16 to 22 & 7 to 13 \\
\hline INEFFECTIVE: & 9 to 15 & 1 to 6 \\
\hline $\begin{array}{l}\text { NEEDS IMMEDIATE ATTEN- } \\
\text { TION }\end{array}$ & $<9$ & 0 \\
\hline
\end{tabular}

The norms indicate that the athletes are performing much better at $40 \mathrm{~cm}$ than at 6 metres, but it also means that fusional demand seems to be less at distance than at near

Table 8: The norms obtained for Central - Peripheral Awareness with the use of the Acuvision 1000

\begin{tabular}{|l|c|}
\hline & Number of correct responses in 1 minute \\
\hline SUPERIOR: & $>58$ \\
\hline ABOVE AVERAGE: & 56 to 58 \\
\hline AVERAGE: & 53 to 55 \\
\hline INEFFECTIVE: & 44 to 52 \\
\hline $\begin{array}{l}\text { NEEDS IMMEDIATE ATTEN- } \\
\text { TION }\end{array}$ & $<44$ \\
\hline
\end{tabular}

The results obtained indicate that elite athletes perform well on this visual skill and it may well be an important skill in sports performance.

Table 9: The norms obtained for Eye-Hand-Coordination on the Wayne Saccadic Fixator

\begin{tabular}{|l|c|c|}
\hline & $\begin{array}{c}\text { Pro-action } \\
\text { of correct responses in } \\
1 \text { minute }\end{array}$ & $\begin{array}{c}\text { Re-action } \\
\text { number of correct re- } \\
\text { sponses in 1 minute }\end{array}$ \\
\hline SUPERIOR: & $>52$ & 30 \\
\hline ABOVE AVERAGE: & 44 to 52 & 29 \\
\hline AVERAGE: & 36 to 43 & 29 \\
\hline INEFFECTIVE: & 28 to 35 & 27 to 28 \\
\hline $\begin{array}{l}\text { NEEDS IMMEDIATE ATTEN- } \\
\text { TION }\end{array}$ & $<28$ & $<27$ \\
\hline
\end{tabular}

There is a reasonable spread on the pro-action results indicating that this skill may be sport specific. It may thus be highly applicable in certain sports while in other sports it may not play a role at all. With the re-action part of the test there was a maximum score of 30 that could be achieved and $80 \%$ of the athletes did achieve this. 
Table 10: The norms obtained for Eye-Body Coordination with a balance board that was connected to a Wayne Saccadic Fixator

\begin{tabular}{|l|c|}
\hline & $\begin{array}{c}\text { Number of correct responses in 1 } \\
\text { minute }\end{array}$ \\
\hline SUPERIOR: & $>37$ \\
\hline ABOVE AVERAGE: & 32 to 37 \\
\hline AVERAGE: & 27 to 31 \\
\hline INEFFECTIVE: & 22 to 26 \\
\hline $\begin{array}{l}\text { NEEDS IMMEDIATE ATTEN- } \\
\text { TION }\end{array}$ & $<22$ \\
\hline
\end{tabular}

These results were also evenly spread suggesting that it may not be an important skill in certain sports or that this ability had been neglected in the training programmes.

Table 11: The norms obtained for Visual Response Time with the use of the Wayne Saccadic Fixator

\begin{tabular}{|l|c|c|}
\hline & $\begin{array}{c}\text { Right hand } \\
\text { time in seconds }\end{array}$ & $\begin{array}{c}\text { Left hand } \\
\text { time in seconds }\end{array}$ \\
\hline SUPERIOR: & $<0.268$ & $<0.247$ \\
\hline ABOVE AVERAGE: & $0.268-0.397$ & $0.247-0.378$ \\
\hline AVERAGE: & $0.398-0.526$ & $0.379-0.509$ \\
\hline INEFFECTIVE: & $0.527-0.656$ & $0.510-0.640$ \\
\hline $\begin{array}{l}\text { NEEDS IMMEDIATE ATTEN- } \\
\text { TION }\end{array}$ & $>0.656$ & $>0.640$ \\
\hline
\end{tabular}

The results obtained for the left hand were slightly better than that obtained when the athletes used their right hands. The big difference between the superior and needs immediate attention categories may again be because of sport specific requirements.

Table 12: The norms obtained for Visual Adjustability with the use of 20 prism dioptres lenses in the base up, base down, base left and base right direction.

\begin{tabular}{|l|c|c|c|c|}
\hline & $\begin{array}{c}\text { Base up } \\
\text { number of } \\
\text { attempts }\end{array}$ & $\begin{array}{c}\text { Base down } \\
\text { number of } \\
\text { attempts }\end{array}$ & $\begin{array}{c}\text { Base right } \\
\text { number of } \\
\text { attempts }\end{array}$ & $\begin{array}{c}\text { Base left } \\
\text { number of } \\
\text { attempts }\end{array}$ \\
\hline SUPERIOR: & 1 & 1 or 2 & $<4$ & $<4$ \\
\hline ABOVE AVERAGE: & 2 to 4 & 3 to 5 & 4 to 7 & 4 to 7 \\
\hline AVERAGE: & 5 to 6 & 6 to 8 & 8 to 9 & 8 to 9 \\
\hline INEFFECTIVE: & 7 to 8 & 9 to 12 & 10 to 12 & 10 to 14 \\
\hline $\begin{array}{l}\text { NEEDS IMMEDIATE } \\
\text { ATTENTION }\end{array}$ & $>8$ & $>12$ & $>12$ & $>14$ \\
\hline
\end{tabular}

The athletes adjusted far quicker when the object was displaced vertically compared to when it was displaced horizontally. 
Table 13: The norms obtained for Visual Concentration with the use of the Acuvision 1000

\begin{tabular}{|l|c|}
\hline & Number of lights correctly detected \\
\hline SUPERIOR: & $>50$ \\
\hline ABOVE AVERAGE: & 42 to 50 \\
\hline AVERAGE: & 34 to 41 \\
\hline INEFFECTIVE: & 26 to 33 \\
\hline $\begin{array}{l}\text { NEEDS IMMEDIATE ATTEN- } \\
\text { TION }\end{array}$ & $<26$ \\
\hline
\end{tabular}

The wide span in the results obtained indicates that athletes may vary considerable with regards to this visual skill.

Table 14: The norms obtained for Visualization with the use of the Getman Manipulation Test

\begin{tabular}{|l|c|}
\hline & Number of correct responses \\
\hline SUPERIOR: & 12 \\
\hline ABOVE AVERAGE: & 10 or 11 \\
\hline AVERAGE: & 9 \\
\hline INEFFECTIVE: & 7 or 8 \\
\hline $\begin{array}{l}\text { NEEDS IMMEDIATE ATTEN- } \\
\text { TION }\end{array}$ & $<7$ \\
\hline
\end{tabular}

Judging from the results, athletes' ability to mentally manipulate images seems to be an important skill since they scored relatively high in this test.

\section{Discussion}

The rapid expansion of sport vision services in the USA since the early 1980's resulted in a need for a standardized sport vision testing battery. Christenson and Winkelstein ${ }^{8}$ were among the first to propose an extensive testing procedure. Yet all these studies ${ }^{5,6,8}$ had one common flaw in that they did not establish any norms for these visual skills or did so in an arbitrary fashion. As a result of this it was difficult to substantiate the claims that were made with regards to visual enhancement. It resulted furthermore in severe criticism by sport optometrists and sport scientists regarding the results to be anecdotal and consequently subject to bias and expectancy effects ${ }^{9}$. Therefore the establishment of clinically proven norms for the various skills is seen as an important element in the visual enhancement debate. There were also no specific protocol and different authors were using different tests that make it almost impossible to compare results. Therefore this study also reports on the proto- cols used in obtaining the various norms. The discussion will thus comment on both the protocols and the norms obtained.

Visual skills can be divided into three different sections. The first involve the health and accuracy of the input section. The second section involves the analysis of the information received by the athlete, and how the athlete handles this information. The third section involves the output system of the athlete, and the way in which the athlete will carry out a required task. These norms were obtained by physically testing the elite athletes' performance on the different tests. This study does not regard these norms to be applicable for all sports since different sports demand different visual requirement levels. The fact that only elite athletes were involved in this study however indicates what high demands the sport environment may put on the visual skills. Furthermore no distinction was made on the basis of gender or age. These variables will certainly be explored in future studies. 


\section{Static Visual Acuity}

This is defined as the resolving power of the eye, or the ability to see two objects as being separate when these objects are both static $\left(\right.$ Grosvenor $\left.{ }^{10}\right)$. It is thus the ability to distinguish detail. The results were calculated by the mean and standard deviation method. The main reason was that a very high percentage of athletes had the same VA. This caused some of the categories to have the same values when using the percentage method and therefore some categories will not have any athletes categorized in them and therefore render the classification meaningless. The results clearly indicate that elite athletes do have good central vision. Whether such a high level of static visual acuity is required for all elite athletes is a matter that requires further investigation.

\section{Dynamic (kinetic) Visual Acuity (DVA)}

Weissman and Freeburne ${ }^{11}$ described DVA as the ability to resolve detail when there is relative movement between the observer and the object being viewed. A Wayne T-Scope Rotator was used to test the DVA. The athlete would stand three metres from the screen with the projected image. A Snellen chart was used, with a rotary prism. The chart would move in a circular motion, while the athlete was standing in a stationary position. The speed, at which the chart was moving, was constantly kept at $78 \mathrm{rpm}$. The athlete was asked to read the smallest line he/she could see, while keeping his/her head stationary. This test was first performed monocularly and then binocularly. Here the mean and standard deviation method was again the method of choice, due to the fact that about $50 \%$ of the athletes had a dynamic VA of $6 / 6$. That caused the average category to have no athletes categorized in it. According to the percentage method, average categories consists of all the athletes that had a score that could be categorized in the $70 \%-50 \%$ range. Almost $50.0 \%$ of the athletes were categorized in the above average category, which caused it to overlap the average category. As it has been the case with static visual acuity, dynamic visual acuity norms are high. The norms for the two eyes are exactly the same and slightly better binocularly than for the monocular situation. Dynamic VA is not applicable to all athletes since the results will not affect the performance of, for instance, target shooters or swimmers. The results do however indicate that elite athletes can detect moving objects and identify them very accurately.

\section{Contrast Sensitivity}

Contrast sensitivity measures the ability of the individual's visual system to process temporal or spatial information about objects and their background under varying lighting conditions. Contrast sensitivity measurements indicate the least amount of contrast required to detect a visual stimulus $\left(\right.$ Grosvenor $\left.{ }^{10}\right)$. A Functional Acuity Contrast Test (F.A.C.T.) was used to test the contrast sensitivity. The different rows on the chart presents different spatial frequencies, with row A being of low spatial frequency and row $\mathrm{E}$ a high spatial frequency. Within a given row the contrast is reduced from left to right. The athlete stood three metres from the chart and the task of the athlete is to report the orientation of each grating in a row, which can either be slanting to the left, vertical or to the right. The mean and standard deviation method exceeded the maximum that could be obtained. Therefore no athletes could be categorized in any of the superior categories, which render it impossible to use and therefore the percentage method was employed. The fact that elite athletes have a high contrast sensitivity profile can be expected because of the high visual acuity values. The question still remains to be answered is, whether participation in sport enhances contrast sensitivity function, or do people become elite athletes because of their superior contrast sensitivity abilities.

\section{Colour Discrimination}

There are two kinds of photoreceptor cells in the eye: cone and rod cells. The rod cells which outnumber the cones are more sensitive to light and permit vision in dim light. Rod cells do not provide colour vision or sharp images; this is why objects look gray and fuzzy when viewed in dim light. Cone cells, by contrast, operate best in bright light and provide for our high-acuity colour vision (Marieb and Mallatt ${ }^{2}$ ). The athletes' colour vision was tested with the Farnsworth D-15 colour vision test. The test is made up of 15 colour samples. Most of the athletes $(79.9 \%)$ did not have a colour deficiency. This caused the above average and the average categories to fall away, and the athletes to be categorized in only three categories. The mean and standard deviation method was used, because when using the percentage method all the athletes were categorized in only one category. The sport that the athletes participate in must be taken into account, to decide if a lack in colour discrimination 
may impede the athlete's performance. According to this study, $11.4 \%$ of the athletes were categorized in the needs immediate attention category and all of them were males. Previous studies have shown that $8 \%$ of males and $0.64 \%$ of females do have a colour anomaly with red-green abnormalities the most common problem $\left(\right.$ Voke $\left.^{12}\right)$.

\section{Stereopsis}

Judgments of depth and distance are visual demands of virtually all sports that involve target or competitor movement. While depth perception and stereopsis are often used indiscriminately, there is a small but definite difference between them. According to Grosvenor ${ }^{10}$ stereopsis is the ability to perceive depth, on the basis of retinal disparity clues in the two eyes while depth perception can be achieved even in monocular subjects with the assistance of clues arising from previous knowledge. The Randot Stereo Test was executed with polarized lenses at $40 \mathrm{~cm}$. The athlete placed the polarized lenses over his prescription lenses if he wore any. No time limitation was placed on the athletes. The mean and standard deviation method could not be used, because the values calculated for the two top categories were less than zero seconds of arc. These values were due to the fact that there was a maximum score that an athlete could obtain. Most of the other tests do not have a maximum, the better the visual skill of the athlete, the higher the score would be. More than half of the athletes (52.5\%) achieved the maximum score for stereopsis, which indicates that elite athletes do have excellent stereopsis. A debate however is still continuing regarding stereopsis and if it can be improved through training or not (Abernethy $\left.{ }^{3}\right)$.

\section{Focus Flexibility (Accommodation)}

This is ability to quickly change accommodative and vergence postures and is one of the visual demands of competitive sport, especially in those sports that the athlete needs to focus on competitors, target objects, playing boundaries and even goal posts. Accommodation is defined as the ability of the eye to focus clearly on objects at various distances, using the crystalline lens $\left(\right.$ Grosvenor $\left.^{10}\right)$. The focus flexibility test was carried out at near $(40 \mathrm{~cm})$ and at far $(6$ metres). Flippers (+2.00 dioptre and -2.00 dioptre) were used binocularly at $40 \mathrm{~cm}$, while the athlete looked at a 20/40 reduced Snellen VA line. At $6 \mathrm{~m}$ the athlete looked at a 6/12 line, while plano and -2.00 lenses were used in the flipper. The number of cycles completed in one minute were recorded. The mean and standard deviation method was used to calculate the values. Although both methods could have been used, the number of athletes categorized in each category using the mean and standard deviation method was more evenly spread than the percentage method's categories. Focus flexibility is definitely one of the visual abilities that can improve through training. Only $2 \%$ of the athletes tested were categorized in the superior category. Most of the athletes were categorized in the average or ineffective categories, indicating that elite athletes probably do not require a superior accommodative and vergence system, in so far as the focus flexibility test actually is able to evaluate the complicated accommodative-vergence system.

\section{Fusion Flexibility (Binocularity)}

Fusion can be divided into motor and sensory fusion. Sensory fusion is the process were the visual stimuli image on the two retinas are combined into a single percept. Grosvenor ${ }^{10}$ described motor fusion as the movement made by the eyes in response to disparate retinal stimuli, in order to maintain single binocular vision. To evaluate fusion flexibility flippers were used with 6 base-in prisms on the top, and 12 base-out prisms at the bottom of the flipper. The same flipper was used for the near and the far tests. The athlete viewed the 6/12 VA line on a Snellen chart, when the test was performed at $6 \mathrm{~m}$. At $40 \mathrm{~cm}$ the athlete viewed a 20/40 reduced SnellenVA line. The numbers of cycles that the athlete could complete in one minute were recorded. Again the mean and standard deviation method was used because of the more evenly spread of athletes in the different categories. Most of the athletes were categorized in the average and ineffective categories, raising the question about the importance of fusion flexibility the visual performance of the athlete.

\section{Central - Peripheral Awareness}

This is the ability of the athlete to maintain focus on the central task, like looking at a ball, yet be aware of other objects to the side. Central and peripheral awareness is extremely important in any sport where there are two or more players in a team ${ }^{5}$. Central and 
peripheral awareness must not be confused with field of vision, which is the entire extent of the visual environment that can be seen without a change in fixation $^{5}$. The Acuvision 1000 was used to test the peripheral central-peripheral awareness of the athletes. The middle of the instrument should be placed at eye level for each individual athlete. The athlete was instructed to maintain fixation at the center of the instrument as the lights illuminated randomly in his/her periphery. If the athlete moved his/her fixation (in other words, looked around to the lights) more than twice, the test was stopped and started over again. The speed of the Acuvision 1000 was set at two, the fixation light was 'on', and with a visual display of 60 random lights. The maximum score that can be obtained for this test is 60 . The superior category has a calculated value of 67.66 when using the mean and standard deviation method, which cannot be achieved. Therefore it was necessary to use the percentage method to calculate the values. The majority of the athletes were categorized in the above average category which confirms that elite athletes do have above average to superior central-peripheral awareness abilities.

\section{Eye-Hand-Coordination}

Visual-motor performance assessment is one of the most important components in sports vision assessment. According to Elmurr ${ }^{13}$ this includes eye-hand coordination (E-H), eye-body coordination, visual response time and peripheral awareness reaction time. Paillard ${ }^{14}$ stated that E-H coordination could be defined as a "perceptual-motor skill involving the integration and processing in the central nervous system of visual and tactile information so that purposeful motor movements can be made'. The Wayne Saccadic Fixator was used to test pro-action and re-action of the athlete. The middle of the instrument was placed at eye level, with the athlete standing about arm's length away. The difference between the pro- and reaction being that with the pro-action test, the lights went on randomly for 30 seconds, and remained at a specific location until the athlete touched the light. With the re-action test the light remained at a specific location for one second, before moving on to the next location. Even if the athlete did not touch the light in one second, it still moved on to the next position. The number of lights the athlete touched in 30 seconds was recorded. When the pro-action time of the athlete was tested, the maximum score did not come into play since the time factor became the limiting factor and not the number of lights touched. Therefore the mean and standard deviation method was used to calculate the values. The re-action test however has a maximum score of 30 , which most of the athletes achieved. Therefore the percentage method was used to calculate the values. It stands to reason that this test may not be sensitive enough to provide a proper indication of re-actions times. The results also indicate that pro-actions times provide a far better indication of eye-hand coordination ability, suggesting that the re-action part of the test to even be excluded in future studies. E-H coordination is extremely important in the majority of sports in particular in fast ball sports. Not only the preciseness of the movement but also the time it takes to complete the movement (Elmurr $\left.{ }^{13}\right)$. Skill acquisition implies a learning process, and Elmurr ${ }^{13}$ was able to show that E-H coordination is trainable. He even claims that this training can be transferred to improved 'on field performance'.

\section{Eye-Body Coordination}

The demands of competitive sport frequently involve shifts in the centre of the balance of the body in response to changing visual information. The Eye-Body (E-B) coordination test changes the visual stimulus, and then measures the efficiency of an athlete to adjust his/her balance, as explained Sherman and Gardner ${ }^{15}$. The test instrument was the Wayne Saccadic Fixator, which was connected to a balance board that was placed about one meter from the wall on which the instrument was placed. The athlete balanced on the balance board. It was explained to the athlete that four lights would go on randomly on the Wayne Saccadic Fixator, at the 3, 6, 9 and 12 o'clock positions. As a light went on the athlete was required to shift balance, in order to press the balance board against the floor, corresponding to the direction associated with the illuminated light. The mean and standard deviation method was again more applicable since this test does not have any maximum or minimum value restrictions. It was interesting to note that $40.9 \%$ of the athletes tested were categorized in the ineffective categories, indicating a lack of good E-B coordination in most athletes. This can either be that for several of the athletes tested this is not an important visual skill for their particular sports or that this may be an area that has been neglected in training programmes. 


\section{Visual Response Time}

Response to visual information and the speed of reaction is critical in most fast, dynamic sports such as tennis. Visual reaction speed is defined as the elapsed time between the onset of a visual stimulus and the initiation of a motor response to the stimulus, which is about 200 milli-seconds while response speed is defined as the elapsed time between the onset of a visual stimulus and the completion of a motor response to that stimulus (Coffey and Reichow ${ }^{6}$ ). The Wayne Saccadic Fixator was used to test the horizontal visual response time of the left and right hands. The athlete was positioned in front of the panel and asked to press the light at the 9 o'clock position with his/her right hand when he/she was ready, move his/her hand as rapidly as possible to the 3 o'clock position, and to press that light. Exactly the same procedures were followed for the left hand. Seven trails were given for each hand with the fastest time achieved, recorded for each hand. The response values calculated for the left hands were quicker than the right hands. This may simply be as a result of the testing procedure itself. With the left hand the movement required was a simple left to right movement whereas the right hand had to move across the body. This test again emphasises the importance of standardised protocols to avoid the wrong conclusions been drawn from the testing results. The mean and standard deviation method was again found to provide the most meaningful results. The majority of athletes were categorized in the average category and this may be a limiting factor in their sports performance. Coffey and Reichow 6 found that reaction and response speeds might be significantly improved through training and the results of this study indicates a need for such intervention programmes.

\section{Visual Adjustability}

Changes in the surroundings or the environment test the flexibility of the athlete's visual system, which allows him/her to rapidly adjust and guide the body's motor responses. The efficiency of the motor responses will be determined by the time it takes the visual system to adjust to these changes in demands. Planer ${ }^{5}$ stated that the inability of an athlete to adjust to changes would cause the performance of the athlete to be unpredictable and inconsistent. The athlete wore yoked prisms of 20 prism dioptres while performing this task. This will cause the visual world to be displaced up (with the base down prism), down (with base up prism), left (with base to the right) or right (with the base to the left) according to the direction of the prisms. The athlete should try to hit a target, which was six metres away, with a tennis ball. The target used was an A4 page with an X in the middle. The number of attempts to hit the cross was recorded, with the base of the prism in all four directions. Because there was a minimum in this test (the athlete can not hit the target in 0 or less attempts), the mean and standard deviation method calculated negative values for the superior category. This meant that the 'percentage' method was used to categorize visual adjustability. The appropriateness of this test is still under investigation, and whether results in this test could be related to on field performance.

\section{Visual Concentration}

Visual concentration is the ability to pay constant attention to visual stimuli for a specific period of time. According to Runninger ${ }^{16}$, visual concentration on the ball is even more important than the concept of eyes on the ball which only refers to the point of focus. He found that an athlete could catch or hit a ball successfully only using visualization and peripheral vision, without having his eyes on the ball (closing his eyes), as long as his visual concentration was on the ball. The visual concentration test is similar to the centralperipheral awareness test. Although there is a maximum score that the athlete can obtain in this test, none of the athletes achieved this score of 60 . Therefore the mean and standard deviation method was used. The Acuvision 1000 was used, and the athlete was instructed to touch the lights as quick as possible, the moment he/she saw them in his/her peripheral vision. The difference however between the two tests is that the athlete must only strike the lights when the green central fixation light is on, and not when it is off. The same speed and mode was used as with the centralperipheral awareness test, but the fixation used was active thus providing a measure of visual concentration. Most of the athletes scored average for this test and since Navon ${ }^{17}$ showed that visual concentration is the driving force behind arousal and selective attention more emphasis should placed on developing this skill.

\section{Visualization}

Visualization forms a major component of every sport performer's preparation for competition. Sher- 
man and Gardner ${ }^{15}$ studied visualization and defined it as the ability to form a mental image of an object not presented to the eyes. This is an important skill that allows athletes to retrieve previously stored movement patterns and response plans required for specific play situations. The Getman Manipulation Test was used, which consist of four figures. The athlete looked at these figures and answered the following questions:

1. If you were to look at this figure from behind what will it look like to you?

2. If you were to flip this figure upside down, what will it look like to you?

3. If you were to look at this figure from behind, and it was flipped upside down, what will it look like to you?

The athlete was given a card with four possible answers on it. The same three questions were asked of the four different figures, which meant the maximum score the athlete could achieve was 12 . Therefore the percentage method was used to calculate the values for the different categories. If the athlete hesitated to give the answer but was nonetheless correct, it was recorded as a correct answer. The problem with this visualization test is that it is not proven to be a good measure for determining how well an athlete can visualize a required motor response. It does, however provide a good measure of the athlete's ability to mentally modify a given visual display.

\section{Conclusion}

This study succeeded in establishing specific protocols and the norms that can be obtained for the different visual skills with the use of these tests. The results showed that the mean and standard deviation method is more applicable in tests where no minimum and/ or maximum values can be obtained. For such cases the percentage method is the only other alternative. The norms obtained suggest that not all elite athletes present with superior visual systems. It highlights the question that is often asked - do elite athletes develop a superior visual system or are they elite athletes because they have a superior visual system and/or can the visual system be trained? Furthermore, the question persists as to whether training of the visual system would transfer to improved sports performance. These areas require further investigation and clarification.

\section{Acknowledgement}

The authors would like to thank the High Performance Programme of the South African Sports Commission for their support and allowing us to publish these results.

\section{References}

1. Reichow AW, Stern NS. Optometric trends in sports vision. Optometric Extension Program Foundation. Curriculum II. 198659 pp 355-368.

2. Marieb EN, Mallat J. Human Anatomy. California: Benjamin/Cummings, 1992, pp 415-423.

3. Abernethy B. Training the Visual-Perceptual Skills of Athletes. American Journal of Sports Medicine 199624 p 89

4. SISA. Sports Information and Science Agency. Sport Sponsorships. South African Sports Commission 2000, p13.

5. Planer PM. Sports Vision Manual. International Academy of Sports Vision. Harrisburg. 1994.

6. Coffey B, Reichow AW. Optometric evaluation of the elite athlete: The Pacific Sport Visual Performance Profile. Problems in Optometry 1990132 - 58.

7. Buys JHC. The development of norms and protocols in sports vision evaluations. Masters Thesis, Rand Afrikaans University, Johannesburg, South Africa 2002.

8. Christenson GN, Winkelstein AM. Visual skills of athletes versus non-athletes: development of a sports vision testing battery. J Am Optom Assoc 1988599 666-675.

9. Wood JM, Abernethy B. An assessment of the efficacy of sports vision training programs. Optometry and Vision Science 1997748 646-659.

10. Grosvenor T. Anomalies of Refraction: Primary Care Optometry. Oxford: Butterworth Heinemann 1996 pp 12 17, 175, 236 - 246.

11. Weissman S, Freeburne CM. Relationship between static and dynamic visual acuity. Journal of Experimental Psychology 196570141 - 146.

12. Voke J. Colour Vision Testing in Specific Industries and Professions. London: Keeler 1980.

13. Elmurr P. Assessing and Training Eye-Hand Coordination Sports Vision 20001638 - 10.

14. Paillard J. Basic neuro-physiological structures of eye-hand coordination. In: Bard, C., Fleury, M., Hay, eds. Development of Eye-hand Coordination. 1990, pp 26 - 74.

15. Sherman A, Gardner JJ. Visual requirements in sport. In: DFC Loran \& CJ MacEwan, eds. Sports Vision. London. Butterworth Heinemann, 1995.

16. Runninger J. Visual concentration: Coach and Athlete. 197537 pp 18 - 37.

17. Navon D. Attention division or attention sharing? In: Attention and Performance XI MI Posner \& OSM Martin eds. Lawrence Erlbaum Associates Hillsdale New York. 1985 pp $74-88$. 